\title{
FORMAÇÃO DE PROFESSORES DE HISTÓRIA: IMPLICAÇÕES A PARTIR DA BNCC E DA DCN-BNC
}

\author{
Renilda Vicenzi $i^{1}$ \\ Bruno Antonio Picoli ${ }^{2}$
}

\begin{abstract}
Resumo: O objetivo deste artigo é analisar as implicações da Base Nacional Comum Curricular (BNCC) e das Diretrizes Curriculares Nacionais para a Formação Inicial de Professores para a Educação Básica e a Base Nacional Comum para a Formação Inicial de Professores da Educação Básica (DCN-BNC) na formação de professores de História. Realiza pesquisa documental e bibliográfica. Conclui que as recentes reformas operam um reducionismo na formação docente com sérias implicações que não se limitam à sala de aula. Afirma que a formação de professores de história que, no seu fazer, se recusam a ser meros técnicos perseguidores de melhorias mensuráveis nos indicadores de testes sistêmicos implica assunção da responsabilidade ética da desobediência por parte dos docentes dos cursos de licenciatura em história.
\end{abstract}

Palavras-chave: BNCC. DCN-BNC. Ensino de História. Formação de professores. Desobediência.

\section{HISTORY TEACHERS EDUCATION: IMPLICATIONS FROM BNCC AND DCN-BN}

\begin{abstract}
This article seeks to analyse the National Common Curricular Base's and the National Curricular Guidelines for Initial Teacher Education of the Basic Education and National Common Base for Initial Teacher Education of the Basic Education's implications in the education of history teachers. Conducts documentary and bibliographic research. It concludes that the recent reforms operate a reductionism in teacher education with serious implications that are not limited to the classroom. It states that the education of history teachers who, in doing so, refuse to be mere technicians in the sense of achieve measurable improvements in systemic test indicators implies an assumption of the ethical responsibility for disobedience on the part of teachers of undergraduate courses in history.
\end{abstract}

Keywords: BNCC. DCN-BNC. History Teaching. Teacher Training. Disobedience.

\section{FORMATION DES PROFESSEURS D'HISTOIRE: IMPLICATIONS DU BNCC ET DU DCN-BNC}

Résumé: Le but de cet article est d'analyser les implications de la Base Nationale du Curriculum Commun (BNCC) et des Lignes Directrices Nationales pour la formation initiale des enseignants à l'éducation de base et de la Base Nationale Commune pour la formation

\footnotetext{
${ }^{1}$ Possui graduação em História pela Faculdade de Filosofia Ciências e Letras de Palmas, especialização em Desenvolvimento e Integração da América Latina - Unicentro, aperfeiçoamento em História pela UPF e em Arqueologia: Processos Interdisciplinares pela URI. Mestrado em História pela Universidade de Passo Fundo. Doutorado em História pela UNISINOS. É professora Adjunta da UFFS - Campus Chapecó. Tem experiência na área de História, com ênfase em História do Brasil Colônia, Império e Primeira República, atuando principalmente nos seguintes temas: relações de trabalho, escravidão e liberdade, migrações e colonização.

${ }^{2}$ Professor da Área de Ensino de História no Curso de Licenciatura em História da Universidade Federal da Fronteira Sul (UFFS), Campus Chapecó. Doutor em Educação pela Pontifícia Universidade Católica do Rio Grande do Sul (PUCRS) e Mestre em História pela Universidade de Passo Fundo (UPF). Tem interesse em Filosofia da Educação e Filosofia e Teoria do Ensino da História, com ênfase nas discussões sobre Educação e Violência, Educação e Democracia, Temas Sensíveis, Diálogo, Educação para a Paz, Ética da Responsabilidade e Contraeducação.
} 
initiale des enseignants à l'éducation de base (DCN-BNC) dans la formation des professeurs d'histoire. Effectue des recherches documentaires et bibliographiques. Il conclut que les récentes réformes opèrent un réductionnisme de la formation des enseignants avec de graves implications qui ne se limitent pas en salle de classe. Il indique que la formation des professeurs d'histoire qui, ce faisant, refusent d'être de simples techniciens à la recherche d'améliorations mesurables des indicateurs de test systémiques implique la prise en charge éthique de la désobéissance de la part des enseignants des cours de licenciature en histoire.

Mots-clés: BNCC. DCN-BNC. Enseignement d'histoire. Formation de professeur. Désobéissance.

\section{FORMACIÓN DE PROFESORES DE HISTORIA: IMPLICACIONES DE BNCC Y DCN-BNC}

Resumen: Este artículo busca analizar las implicaciones de los documentos legales "Base Curricular Nacional Común" y "Pautas Curriculares Nacionales para la Educación Inicial del Maestro de la Educación Básica y la Base Nacional Común para la Educación Inicial del Maestro de la Educación Básica" en el proceso de formación de los maestros de historia. Realiza investigaciones documentales y bibliográficas. Concluye que las reformas recientes operan un reduccionismo en la formación docente con serias implicaciones que no se limitan al aula. Establece que la educación de los maestros de historia que, al hacerlo, se niegan a ser meros técnicos en el sentido de lograr mejoras medibles en los indicadores implica asunción de la responsabilidad ética de la desobediencia por parte de los maestros de los cursos de historia.

Palabras-clave: BNCC. DCN-BNC. Enseñanza de la historia. Formación de profesores. Desobediencia.

\section{Introdução}

Ao refletirmos acerca da educação brasileira, nos vemos em um campo de dualidades, de um lado, professores e alunos lutando cotidianamente para que os processos de ensino e aprendizagem tenham êxito, por outro, o Estado inoperante e fomentador. Do descaso com a educação leva a compreensão que a educação brasileira passa por uma profunda crise de qualidade. Os indicadores, como o Exame Nacional do Ensino Médio (ENEM), o Índice de Desenvolvimento da Educação Básica (IDEB) e demais testes inspirados no Programa Internacional de Avaliação de Estudantes (PISA), mensuram essa crise. O Brasil figura entre os países com o pior desempenho dentre os sistemas avaliados (OCDE, 2019). São recorrentes matérias jornalísticas de circulação nacional que atribuem a responsabilidade pelos maus resultados aos professores (VEJA, 2015). Aos professores de disciplinas de humanidades, em especial os de história, recai ainda outra acusação que os culpabiliza pelo fracasso escolar brasileiro: seriam eles doutrinadores ideologicamente comprometidos (UOL, 2020). Cabe ressaltar que a imprensa nestes casos se aporta em narrativas que ensejam invisibilizar a função do Estado nos processos educativos e 'encontrar' culpados quando os índices não são satisfatórios. 
Os professores brasileiros se veem diante de situações cada vez mais precárias: são mal remunerados em comparação com outros profissionais com a mesma formação no Brasil (INEP, 2018) e em comparação com professores em outros países (OCDE, 2020), são acusados de promover lavagem cerebral nos estudantes (MIGUEL, 2016) ao mesmo tempo em que são vítimas de violência escolar e de ameaças (BBC BRASIL, 2019). Ao mesmo tempo que fica evidente o crescimento de sua responsabilidade frente ao futuro do país, em razão de redução da densidade da democracia brasileira pelo crescimento acelerado de movimentos anti-intelectuais que negam as descobertas científicas nas mais diferentes áreas (PICOLI; RADAELLI; TEDESCO, 2020). No campo específico da história, cresce a descrença na democracia e, consequentemente, o apelo por alternativas políticas que implicam ruptura das instituições republicanas através de golpe militar (COUTO NETO, 2019). Além disso, galgam espaço movimentos que questionam as políticas afirmativas de inclusão de negros, indígenas e demais minorias em espaços e posições até há pouco tempo exclusivas à população branca, normalmente homens (SILVA, 2018).

Com o declarado objetivo de melhorar a qualidade da educação brasileira, reformas curriculares, tanto para a educação básica, quanto para a formação de professores, foram empreendidas entre 2015 e 2019 (PICOLI; VICENZI, 2020). Para a Educação Básica, a reforma curricular foi apresentada como uma base normativa, vinculante e que exige o alinhamento de todas as demais políticas no campo educacional, passando pela produção didática, financiamento e formação de professores: a Base Nacional Comum Curricular - BNCC (BRASIL, 2018). Em razão da exigência de alinhamento, entre dezembro de 2018 e dezembro de 2019, apresentouse, discutiu-se e aprovou-se a reforma dos cursos de formação de professores em nível superior: as Diretrizes Curriculares Nacionais para a Formação Inicial de Professores para a Educação Básica e a Base Nacional Comum para a Formação Inicial de Professores da Educação Básica - DCN-BNC (BRASIL, 2019).

O objetivo deste artigo é analisar esses dois documentos e refletir sobre os problemas e as possibilidades para a formação de professores de história que, no seu fazer, agem com ética, reponsabilidade e decoro e, portanto, se recusam a ser meros técnicos perseguidores de melhorias mensuráveis nos indicadores de testes sistêmicos. Está organizado em três partes: na primeira, discute a BNCC e suas reverberações no ensino de História; na segunda, analisa as determinações da DCN-BNC para a formação de professores; e, na terceira, reflete sobre as implicações desses documentos 
normativos na formação de professores de história, assim como sobre as possibilidades de uma formação crítica que entenda o professor como um intelectual, como um indivíduo que toma decisões curriculares no seu fazer.

\section{A BNCC da educação básica: a história como uma lista de conteúdos que não problematiza a vida em sociedades complexas e desiguais}

A Lei de Diretrizes e Bases da Educação Nacional, Lei no 9394, de 1996, no capítulo II, Art. 26, aponta para a realização de uma Base Nacional Comum: "Os currículos do ensino fundamental e médio devem ter uma base nacional comum, [...]". A partir daí, foram elaborados documentos orientadores: os Parâmetros Curriculares Nacionais (PCNs - 1997 e 1998) para o Ensino Fundamental, os Parâmetros Curriculares Nacionais para o Ensino Médio (PCNEM - 2000), as Diretrizes Curriculares Nacionais Gerais para a Educação Básica (DCNs - 2010), em 2011 as Diretrizes Curriculares Nacionais para o Ensino Fundamental de 9 (nove) anos, em 2012 as Diretrizes Curriculares Nacionais para o Ensino Médio, e em 2015 a apresentação da primeira versão da BNCC.

Mesmo com documentos norteadores das políticas educacionais, a BNCC foi apresentada, discutida e aprovada entre 2015 e 2018, período marcado por grande turbulência política no Brasil que foi sentida no processo de elaboração do documento. Nesse processo, em que se apresentaram três versões para a Base, várias associações de professores e pesquisadores manifestaram preocupação com a sua condução, marcada pela pressa e falta de diálogo com a produção acadêmica nacional e com os professores (PICOLI, 2020). Contudo, no primeiro momento, muitos pesquisadores de diferentes áreas do conhecimento se manifestavam, ainda, entusiastas sobre a construção de um documento norteador, de uma Base Nacional. Alguns, inclusive, se mostraram dispostos a contribuir com o MEC na melhoria do texto (HYPOLITO, 2019).

A partir de 2016 os grupos de trabalho para elaboração da BNCC foram dominados por atores vinculados às entidades empresariais reformadoras e aos movimentos ultraconservadores que procuram, por diversas estratégias, esvaziar o conteúdo educativo da escola, o que favoreceu o endurecimento da BNCC, a defesa de seu caráter normativo e vinculante às demais políticas do campo, a ênfase na competitividade e no gerencialismo (PICOLI, 2020; ANTUNES, 2019; ZANOTTO, SANDRI, 2018) e a exclusão de temas demasiado importantes em um país complexo como o Brasil, tais como as questões de gênero e sexualidade, as relações étnico-raciais 
e os conflitos sociais produzidos pelo modelo de capitalismo vigente na sociedade brasileira, que caracterizam a terceira e definitiva versão final, apresentada em abril de 2017. Em 2018, acresceu-se ao documento o texto da BNCC para o Ensino Médio (BRASIL, 2018). Hypolito (2019) destaca que a versão definitiva da BNCC apresenta conteúdos retrógrados e conservadores mesmo para as demandas neoliberais que, até a segunda versão, eram hegemônicas.

A Associação Nacional de História (ANPUH), que sempre se posicionou favorável a construção de uma BNCC, manifestou em várias oportunidades preocupações com os encaminhamentos dados pelo documento ao componente curricular História. Em nota de 2016, após a divulgação da segunda versão do documento, a associação manifesta preocupação com o encaminhamento que o componente curricular História recebeu, especialmente "no que diz respeito à retomada de um currículo tradicional já bastante conhecido entre nós" (ANPUH, 2016). Afirma ainda que a segunda versão, que, como se verificou depois, não sofrerá grandes alterações no documento definitivo de 2017, mantém como estrutural o caráter prescritivo, através da enumeração de conteúdos distribuídos cronologicamente entre os diferentes anos escolares da Educação Básica, e a vocação avaliativa, vinculada aos testes sistêmicos. Reivindica, portanto, que a discussão considere a produção acadêmica brasileira no campo do Ensino da História e da Educação de modo geral no sentido de considerar "o desenvolvimento da capacidade autoral de cada professor em sala de aula" (ANPUH, 2016).

As críticas da associação, que reúne pesquisadores e professores de universidades e da educação básica não foram consideradas pelos elaboradores do documento para a terceira e definitiva versão, o que levou a associação a encaminhar uma carta ao Conselho Nacional de Educação (CNE). Na carta, a ANPUH (2017) reafirma suas preocupações e salienta o caráter retrógrado da concepção de História, assim como o sequestro da profissionalidade docente, já que, considerando o caráter prescritivo e a vinculação do currículo aos testes em grande escala, o professor de História é transfigurado em mero técnico aplicador de um currículo estabelecido externamente.

A BNCC está organizada por meio de Competências Gerais, Competências Específicas das Áreas, Competências Específicas de Componentes, e, nesses, Unidades Temáticas, Objeto de Conhecimento e Habilidades. Justifica-se a organização do currículo por competências porque este é o critério referencial "nas avaliações 
internacionais da Organização para a Cooperação e Desenvolvimento Econômico (OCDE) que coordena o Programa Internacional de Avaliação de Alunos (Pisa, na sigla em inglês)" (BRASIL, 2018, p. 13). Em tese, o domínio gradual das habilidades implica aquisição das Competências Gerais. Os elaboradores do documento parecem crer que desenvolvendo as Competências Específicas de cada componente atingir-se-ão as Competências Específicas das Áreas e que, a junção dessas, por sua vez, concretiza a aquisição das Competências Gerais. Tudo isso partindo dos "objetos de Conhecimento e Habilidades". Como se pela mobilização de conhecimentos científicos fosse possível atingir uma atitude ética em um mundo plural e democrático. Em outras palavras, como se a democracia e a ética fossem o produto de um conjunto de ações possíveis de programar.

A educação sustentada em habilidades e competências é transvestida em tecnologia (BIESTA, 2017) e está, quando muito, preocupada com a qualificação para o mundo competitivo e com um tipo de socialização limitada à adaptação. A vinculação das Competências Gerais com os critérios de avaliação dos exames padronizados denuncia que a competência mais importante para os elaboradores da BNCC está omissa, pelo menos textualmente: a competência para competir, para obter resultados (PICOLI, 2020). Pressionados por gestores e pela opinião pública, os professores podem direcionar seus esforços não para ajudar seus alunos a viver de forma adulta e responsável, mas em melhorar os indicadores. Como não é possível mensurar uma atitude ética, mas é possível um dado, o perigo é que a escola deixe de se preocupar com ética e se converta em uma fornecedora de informações mensuráveis, perdendo, assim, sua função educativa (BIESTA, 2009, 2017, 2018; BALL, 2012).

Ao tratar a democracia, os direitos humanos, a pluralidade, o racismo, o combate a violência etc. como objetos do conhecimento (como conteúdos) e não como problemas com potencial histórico-educacionais e éticos sérios a serem enfrentados por professores e estudantes, a narrativa histórica sustentada pela BNCC, higienizada de polêmicas, induz à naturalização das relações mercadológicas de competição e as competências incidem em competências para melhor se adaptar ao mundo que nega a alteridade e que se pretende universal e naturalizado. Daí porque o palatável argumento de que é um direito das crianças e dos jovens pobres o acesso a mesma educação que as crianças e os jovens de classes sociais elevadas (BRASIL, 2018) se mostra um engodo, já que não se coloca em questão a organização dessa sociedade que cria ricos e pobres. Às crianças e aos jovens pobres resta como alternativa adquirir competências para 
circular em um mundo competitivo que inclui uns excluindo outros, já que a liberdade para criar um mundo novo não é oportunizada (BIESTA, 2017, 2018; GUR-ZE'EV, 2005).

A BNCC procura estabelecer a norma, padronizar a educação e normalizar as relações, isso é assumido pelo próprio documento: “de caráter normativo que define o conjunto orgânico e progressivo de aprendizagens essenciais que todos os alunos devem desenvolver ao longo das etapas e modalidades da Educação Básica” (BRASIL, 2018, p. 7). Além de normativa, a BNCC é declaradamente vinculante. Exige um alinhamento das demais políticas públicas e ações no campo da educação:

a BNCC integra a política nacional da Educação Básica e vai contribuir para o alinhamento de outras políticas e ações, em âmbito federal, estadual e municipal, referentes à formação de professores, à avaliação, à elaboração de conteúdos educacionais (BRASIL, 2018, p. 8).

Dá-se, também, na composição de um currículo normativo para a formação dos professores em nível superior e para a política de produção de suportes didáticopedagógicos. O alinhamento implica que o credenciamento de cursos, a concessão de bolsas, a aprovação de livros didáticos etc. só ocorrerá pela submissão aos valores estabelecidos pela BNCC. Ao reconhecer a importância dos professores para o sucesso dos estudantes, o faz compreendendo o professor como mera peça do processo, uma vez que estabelece que uma das condições para a melhoria dos indicadores é que os professores atuem em conformidade com o que está normatizado pela BNCC. Estabelece, assim, que a primeira tarefa do projeto normalizante " $[. .$.$] de$ responsabilidade direta da União será a revisão da formação inicial e continuada dos professores para alinhá-las à BNCC" (BRASIL, 2018, p. 21). Do que trata a parte que segue.

\section{A DCN-BNC: o professor de história como um técnico aplicador de um currículo prescrito de fora}

Atendendo à exigência de alinhamento à BNCC, o Conselho Nacional de Educação (CNE) publicou o documento DCN-BNC pela Resolução CNE/CP no 2/2019 (BRASIL, 2019) que definem como devem ser organizados os cursos de formação de professores da Educação Básica. Todo o processo de discussão do documento se deu entre dezembro de 2018 e dezembro de 2019 (D’ÁVILA, 2020). Como tem se tornado corriqueiro nos processos que envolvem a legislação em torno da $\mathrm{BNCC}$, o processo de 
elaboração da DCN-BNC foi marcado pela pressa e pela ausência de debate. A DCNBNC não ocupou um vazio normativo. Em vigor, e em implantação, estava a Resolução CNE/CP $n^{\circ}$ 2/2015 (BRASIL, 2015) que estabelecia as Diretrizes Curriculares Nacionais para a Formação de Inicial e Continuada de Profissionais do Magistério da Educação Básica, cuja discussão e elaboração durou quase dez anos e mobilizou parte significativa de pesquisadores e professores, além da produção científica nacional das últimas quatro décadas (ANPUH, 2017; ANPED, 2019).

Nesse processo, a Associação Nacional de Pós-Graduação e Pesquisa em Educação (ANPEd), principal entidade brasileira na área de Educação, publicou uma nota em que elenca um conjunto de razões pelas quais a associação se opõe ao documento DCN-BNC (ANPED, 2019), dentre elas, destacam-se: a) oferece "uma formação de professores "de uma nota só", ou seja, de que a única possibilidade de formação é a que adere à orientação dos pressupostos da BNCC, e que, portanto, oblitera as possibilidades do dispositivo legal anterior que sustenta que a educação nacional está, dentre outras coisas, alicerçada na pluralidade de concepções pedagógicas; b) “desconsidera o pensamento educacional brasileiro" e, assim, sustenta seus objetivos em documentos e exigências de instituições internacionais, como a OECD; c) promove uma formação de caráter tecnicista que ignora a relação indissociável entre teoria e prática; d) desconsidera os contextos de atuação do futuro professor e sua desigualdade pela ênfase na aquisição de competências socioemocionais, especialmente a resiliência e a adaptação; e) promove a secundarização da formação docente, ou seja, não atribui importância à pesquisa e a extensão; e, f) não reconhece o professor como um profissional que toma decisões curriculares, ao contrário, tão só que executa um currículo predeterminado.

Alinhada à lógica da BNCC da Educação Básica, o documento DCN-BNC (BRASIL, 2019), está estruturado a partir de uma lista de competências que os futuros professores devem conquistar. $\mathrm{O}$ alinhamento é ainda mais amplo porque não se limita à Educação Básica. Conforme D’Ávila:

para se formar professores na perspectiva de um currículo por competências acentuadamente praticista, se requererá formadores (docentes dos cursos de licenciatura) alinhados a esta versão. As reverberações ideológicas e formativas pois, deste documento, atinge aos docentes universitários, professores da educação básica e seus alunos, num efeito 'cascata' (D’ÁVILA, 2020, p. 92). 
No Art. $3^{\circ}$ da DCN-BNC (BRASIL, 2019) está disposto o alinhamento e a redução da formação de professores aos princípios da BNCC da Educação Básica: “Com base nos mesmos princípios das competências gerais estabelecidas na BNCC, é requerido do licenciando o desenvolvimento das correspondentes competências gerais docentes". No Art. $4^{\circ}$ encontram-se listadas as competências gerais e as especificidades de cada uma delas: 1) conhecimento profissional, 2) prática profissional e 3) engajamento profissional. Nos parágrafos $1^{\circ}, 2^{\circ}$ e $3^{\circ}$ do Art. $4^{\circ}$ listam-se as competências específicas para cada uma das competências gerais. Para a primeira: "dominar os objetos de conhecimento e saber como ensiná-los", "demonstrar conhecimento sobre os estudantes e como eles aprendem", "reconhecer os contextos de vida dos estudantes", e "conhecer a estrutura e a governança dos sistemas educacionais". Para a segunda: "planejar as ações de ensino que resultem em efetivas aprendizagens", "criar e saber gerir os ambientes de aprendizagem", "avaliar o desenvolvimento do educando, a aprendizagem e o ensino", e "conduzir as práticas pedagógicas dos objetos do conhecimento, as competências e as habilidades". E, por fim, para a terceira: "comprometer-se com o próprio desenvolvimento profissional", "comprometer-se com a aprendizagem dos estudantes e colocar em prática o princípio de que todos são capazes de aprender", "participar do Projeto Pedagógico da escola e da construção de valores democráticos”, e "engajar-se profissionalmente, com as famílias e com a comunidade, visando melhorar o ambiente escolar". Desvela-se a ênfase na prática, não em uma perspectiva articulada com a teoria, mas na redução da didática às práticas de ensino e, no caso da atuação dos professores dos cursos superiores, na prática de ensinar a ensinar (D’ÁVILA, 2020).

Como não faz menção a outros sistemas senão o escolar, o documento procura estabelecer uma neutralidade pseudocientífica através da higienização de questões importantes que afetam a atuação docente. O processo de higienização torna-se mais claro na análise das habilidades docentes, relativas a cada uma das competências específicas. Da mesma forma como ocorre na BNCC da Educação Básica, os elaboradores partem do pressuposto de que a aquisição das habilidades conduz à aquisição das competências específicas e, dessas, às gerais. Na habilidade 3 para competência específica "criar e saber gerir os ambientes de aprendizagem", lê-se: "Construir um ambiente de aprendizagem produtivo, seguro e confortável para os estudantes, utilizando as estratégias adequadas para evitar comportamentos disruptivos" (BRASIL, 2019). O que são comportamentos disruptivos? Diante das injustiças, o 
comportamento disruptivo pode ser o de reivindicar novas formas de conviver. Frente à normalização do racismo, característica da sociedade brasileira, como a própria produção acadêmica sustenta (SCHWARZ, 2019; ALMEIDA, 2019), comportamento disruptivo é questionar as práticas racistas estruturais. Viver em uma democracia é viver na diferença, é viver em conflito, de forma racional e respeitosa, afinal, se compartilha o mundo com pessoas que não pensam da mesma forma (BIESTA, 2017). Em História, o que são comportamentos disruptivos senão a própria ação no tempo em que se está com o objetivo de construir um mundo mais justo? Não é a aquisição de uma lista de habilidades e competências, muito menos de um conjunto mensurável de conteúdos, por si só, que oferecem as condições para isso.

Atentos à necessidade de alinhar a formação docente à BNCC e, comprometidos com o caráter praticista e neotecnicista, os elaboradores da DCN-BNC procuraram normatizar minuciosamente a organização curricular dos cursos de formação de professores. O Art $10^{\circ}$ (BRASIL, 2019), estabelece que "Todos os cursos em nível superior de licenciatura, destinados à Formação Inicial de Professores para a Educação Básica, serão organizados em três grupos, com carga horária total de, no mínimo, 3.200 (três mil e duzentas) horas", o Art $11^{\circ}$ normatiza a carga horária desses grupos e os Art $12^{\circ}$ ao $15^{\circ}$ definem suas características. Embora o MEC afirme que isso não caracteriza subversão do princípio constitucional da autonomia universitária, haja vista que ao estabelecer o mínimo de carga horária prática, a DCN-BNC não impede que as instituições formadoras, especialmente as universidades ampliem a carga horária de seus cursos, outros fatores concorrem nesse processo e, consequentemente, impedem uma formação mais sólida dos futuros professores em nível superior. Para a iniciativa privada, a concorrência com as instituições que ofertam $\mathrm{EaD}$ e com franquias de ensino superior faz com que um curso de licenciatura com mais de 4 anos de duração não seja comercialmente atrativo. Já as universidades públicas, embora possam ampliar seus cursos, não recebem financiamento para as turmas a partir do $9^{\circ}$ semestre. Em ambos os casos, o princípio da autonomia universitária, embora formalmente mantido, se torna inviável.

O Grupo I, normatizado no Art. 12. que compreende a base comum, com carga horária de 800 horas, “deve ter início no primeiro ano do curso a partir da integração das três dimensões das competências profissionais docentes - conhecimento, prática e engajamento profissionais - como organizadoras do currículo e dos conteúdos segundo as competências e habilidades previstas na BNCC-Educação Básica”. São temáticas 
desse grupo, segundo a DCN-BNC, o currículo e a legislação, a BNCC, e a "didática e seus fundamentos". Sobre a didática, a ênfase recai sobre os aspectos técnicos e não sobre a didática enquanto campo epistemológico (D’ÁVILA, 2020). Para a temática da didática, o documento estabelece uma lista de habilidades a serem adquiridas pelo futuro professor, dentre os quais, "a compreensão da natureza do conhecimento", "manejo dos ritmos, espaços e tempos para dinamizar o trabalho de sala de aula e motivar os estudantes", "elaboração e aplicação dos procedimentos de avaliação", "realização de trabalho e projetos" e a "compreensão básica dos fenômenos digitais e do pensamento computacional, bem como de suas implicações nos processos de ensinoaprendizagem na contemporaneidade". Além dessas, são temáticas do grupo I, entre outras, as "metodologias, práticas de ensino ou didáticas específicas dos conteúdos a serem ensinados", a "gestão escolar", a "interpretação e utilização, na prática docente, dos indicadores e informações presentes nas avaliações do desempenho escolar, realizadas pelo MEC e pelas secretarias de Educação", o "desenvolvimento acadêmico e profissional próprio". Para D’Ávila (2020), o fenômeno educativo, foco desse grupo, está reduzido ao conhecimento das práticas, como se as práticas fossem higienizadas da contaminação ideológica da teoria, como se a simples prática, o neotecnicismo e o praticismo, não fossem eles também movimentos profundamente ideológicos.

O grupo II, normatizado no Art $13^{\circ}$, compreende, para o caso dos professores dos anos finais do Ensino Fundamental e do Ensino Médio, como são os professores de História, a parte de estudos específicos de sua área, com carga horária de 1600 horas, e "deve efetivar-se do $2^{\circ}$ ao $4^{\circ}$ ano". O parágrafo $1^{\circ}$ do Art. $13^{\circ}$ estabelece que, nesse grupo, devem ser incluídas a aquisição das seguintes habilidades, dentre outras: "compreensão do conhecimento pedagógico do conteúdo proposto para o curso", "vivência, aprendizagem e utilização da linguagem digital em situações de ensino e de aprendizagem na Educação Básica", "resolução de problemas"; “articulação entre as atividades práticas realizadas na escola e na sala de aula com as que serão efetivadas durante o estágio supervisionado", “alfabetização, domínio de seus fundamentos e domínio pedagógico dos processos e das aprendizagens envolvidas, com centralidade nos resultados quanto à fluência em leitura", "engajamento com sua formação e seu desenvolvimento profissional", e "articulação entre os conteúdos das áreas e os componentes da BNCC-Formação com os fundamentos políticos referentes à equidade, à igualdade e à compreensão do compromisso do professor com o conteúdo a ser aprendido". Centralidade nos resultados, ênfase na articulação entre as práticas, 
compromisso com o conteúdo, excluí o estudante e seus saberes do processo educacional e denunciam o caráter gerencialista do documento.

A ênfase nos resultados e no conteúdo tem direta ligação com a cultura gerencialista das avaliações em larga escala (BALL, 2012; BIESTA, 2017), que fundamentam as decisões curriculares da BNCC que, por sua vez, exige a remodelação dos cursos superiores de formação docente. As licenciaturas, então, estão em um limbo entre um curso técnico de nível médio e um curso superior. Por muito tempo se criticou a formação docente no Brasil como excessivamente bacharelesca, a DCN-BNC, por seu turno, a torna excessivamente técnica (QUEIROZ GUEDES, 2020; GONÇALVES, MOTA, ANADON, 2020; SANTOS, FERREIRA, 2020). De qualquer modo, não é uma licenciatura, não é formação de professores em nível de educação superior. Entendemos que a formação de professores de história, em nível superior, como Licenciados, perpassa conhecimentos das especificidades da História, dos processos pedagógicos, das concepções teóricas, das práticas de ensino, dos eventos históricos, mas também implica envolvimento com pesquisa e extensão, com reflexão teórica autoral do licenciando em formação. Considerando a lista de habilidades que ocupam as atribuições desse grupo, assim como o alinhamento com o que está normatizado na BNCC da Educação Básica, quanto tempo sobra para um futuro professor de história estudar História, teoria da história, historiografia, revisionismo, fonte, tempo, movimento, memória, acontecimento, sequência, periodização, duração, narrativa etc.? Quanto tempo resta para estudar os temas que nos são sensíveis e dos quais não podemos nos esquivar, como a violência de gênero, o racismo, a desigualdade etc.? Quanto tempo resta para envolver-se em pesquisa, em problematizar implicações históricas e educacionais desses temas? Quanto tempo resta para investigações sobre os sentidos de se ensinar história ou de se ensinar os temas que são ensinados em história?

Apesar do caráter praticista já presente nos grupos I e II, é o grupo III que é definido pela DCN-BNC como "prática pedagógica", com carga horária de 800 horas, divididas entre 400 horas de "prática dos componentes curriculares dos Grupos I e II, distribuídas ao longo do curso", ocupando, portanto, parte da carga horária dos grupos I e II, e 400 horas de "estágio supervisionado, em situação real de trabalho em escola" (BRASIL, 2019). A “prática pedagógica" é normatizada pelo Art $15^{\circ}$ e "deve estar intrinsecamente articulada, desde o primeiro ano do curso, com os estudos e com a prática previstos nos componentes curriculares". O neotecnicismo fica claro no parágrafo $5^{\circ}$ do Art $15^{\circ}$, quando define o que o documento entende por "práticas": 
"consistem no planejamento de sequências didáticas, na aplicação de aulas, na aprendizagem dos educandos e nas devolutivas dadas pelo professor". Tal dispositivo reafirma o que está declarado no Art $7^{\circ}$ da DCN-BNC como um dos princípios norteadores da formação docente: "centralidade da prática por meio de estágios que enfoquem o planejamento, a regência e a avaliação de aula, sob a mentoria de professores ou coordenadores experientes da escola campo do estágio".

Reduzir o estágio a mera prática é reduzir o professor a mero aplicador de um currículo. O professor não pensa sobre o que ensina, não é sua atribuição. Ao aplicar o currículo sem tomar decisões curriculares, o professor é mero fantoche, peça substituível, boneco de ventríloquo (Ball 2012). Estágio é pesquisa, implica relação ininterrupta entre teoria e prática, prática e teoria, reflexão teórica sobre a prática, prática indissociável de teoria (PIMENTA, LIMA, 2004). Na nota emitida pela Anped (2019), meses antes da homologação, já se manifesta a preocupação com a redução da formação docente à sua importante, embora não exclusiva, dimensão técnica:

A docência não se reduz à prática de ensino, antes é uma forma de atuação caracterizada como uma prática educativa com dimensões multifacetadas, de modo que os processos formativos não devem se limitar aos conteúdos relacionados ao saber fazer. [...] uma formação voltada para a prática preconiza que é nela que o conhecimento profissional é construído e vai se renovando, desconsiderando a natureza heterogênea desse conhecimento que se firma também em bases teóricas. Ainda, ao se limitar os domínios que influenciam a prática educativa, também se reduz o processo de desenvolvimento da profissionalidade do professor (ANPED, 2019).

A DNC-BNC (BRASIL, 2019), no espírito gerencialista que a acompanha, assim como a BNCC, estabelece avaliações externas para os cursos de formação de professores da Educação Básica. Os Art $25^{\circ}$ e $26^{\circ}$ definem que o Instituto Nacional de Estudos e Pesquisas Educacionais Anísio Teixeira (Inpe) deve, em um prazo de dois anos, elaborar e aplicar um sistema de avaliação in loco e um exame sistêmico para aferir se os estudantes das licenciaturas adquiriram as habilidades e as competências definidas pela DCN-BNC. Não só os documentos (BNCC e DCN-BNC) foram elaborados de forma apressada, como estabelecem uma agenda acelerada para a avaliação dos cursos, atropelando os necessários debates para a reformulação de projetos de cursos que precisam, se democráticos, passar por instâncias colegiadas diversas. Ao atropelar o debate, a DCN-BNC escancara sua face antidialógica e antidemocrática. Considerando que o alinhamento à BNCC e, consequentemente, à DCN-BNC é critério de recredenciamento para os cursos de formação de professores, o 
perigo é que os professores formadores, pressionados por melhores desempenho nos indicadores, dediquem maior atenção ao que é mensurável e menos atenção a uma formação que possibilite pensamento crítico, ação ética e democrática, elementos de difícil, senão impossível aferição em exames sistêmicos (BIESTA, 2017).

A previsão da Anpuh (2017), de que o que estava em curso era, entre outros, "um aviltamento da autonomia docente no planejamento, na escolha e produção de materiais didáticos, no processo avaliativo, em favor de formas rígidas de prescrição curricular que afetam e subordinam a formação inicial docente", se confirma nos princípios e nos fundamentos pedagógicos definidos pela DCN-BNC. O modelo instituído desconsidera a necessidade de enfrentar as questões estruturais de nossa sociedade, de nossa formação histórica, como elementos com potencial educativo. A história é uma lista de conteúdos e o professor, formado nessa concepção, é incapaz de ver para além disso. Pode se tornar incapaz de ver como a Educação Histórica pode ajudar seus alunos a encontrarem soluções democráticas, éticas e cheias de sentido para os problemas que fazem da sociedade brasileira uma das mais desiguais do mundo (ALVAREDO ET ALL, 2018), uma das que mais mata LGBTs (OLIVEIRA, MOTT, 2020) e uma das que mais registram violência doméstica contra mulheres (NOWAK, 2012).

Enfrentar os nossos desafios não é uma questão de conteúdo, de compromisso com os conteúdos a serem ensinados e aprendidos, sequer é uma questão de metodologia de ensino. Com certeza não é uma questão mensurável, aferível em um exame padronizado. É uma questão de qualidade da democracia. Como nada de bom advém de coisas perversas, ou seja, como uma educação democrática não advém de atitudes antidemocráticas, a reforma educacional por que passou o Brasil nos últimos anos não oferece meios para superar nossa condição, ao contrário, interrompe processos que procuravam enfrentar esses problemas, como as Leis 10639/2003 e 11645/2008, que, com a BNCC, correm o risco de tornaram-se letra morta. É preciso reafirmar o conteúdo educacional da escola, assim como o caráter intelectual do professor de história. Sobre essa reafirmação é que se dedica a parte que segue.

\section{Desafios para a formação de professores de história: a desobediência ética}

A quem interessa um ensino de história não reflexivo? A quem interessa a não autonomia do professor? Hoje, a partir da DCN-BNC, em linhas gerais, temos dois elementos vigentes acerca da formação de professores, o primeiro uma formação que 
'formate' o ensinar do professor e segundo uma formação que garanta o 'sucesso' em testes. Em função das diretrizes atuais que nos tolhem uma educação histórica na perspectiva da diversidade, da alteridade e da inclusão, é necessário lembrar que já tivemos, mesmo que parcialmente, liberdade de construir currículos plurais. Em 1996, depois de termos passados décadas sob o jugo do regime civil-militar, de debatermos e avançarmos para a construção da democracia com eleições diretas, não fazia mais sentido continuarmos com uma legislação educacional (lei 5692/1971) que referendava o regime autoritário. Assim diante de um campo de disputas em torno da educação formal, como já mencionado acima, fora promulgada a Lei de Diretrizes e Bases da Educação (LDB) no 9394/1996 (BRASIL, 1996). Essa lei, em seu Art. $3^{\text {o }}$ reza que "O ensino será ministrado com base nos seguintes princípios: [...] II- liberdade de aprender, ensinar, pesquisar e divulgar a cultura, o pensamento, a arte e o saber; III - pluralismo de ideias e de concepções pedagógicas".

Conforme a literatura acerca do ensino de história no Brasil (CAIMI, 2001; BITTENCOURT, 2004), dentre as alterações na área estava a ênfase do ensino de história numa perspectiva crítico reflexiva, articulada à pesquisa. Nesse contexto de abertura, os professores, cuja formação inicial havia ocorrido em tempos ditatoriais, desafiavam-se e se distanciavam do que haviam aprendido nas instituições de ensino superior. Foram tempos de rever conteúdos e metodologias de ensino. De acordo com Bittencourt (2018, p. 142), “Constata-se que houve mudanças significativas pela introdução de novos conteúdos históricos com base em seu compromisso de formação de uma cidadania democrática”. Os documentos/legislação desse período para a educação formal indicam que houve, sem dúvida com limites, possibilidades de diálogo e reflexão que foram construídos ao longo das últimas décadas do século $\mathrm{XX}$, o que possibilitou sua ampliação com as leis 10.639/2003 e 11.645/2008.

Avançávamos, com percalços, para um ensino que se contrapunha a narrativas descontextualizadas e que promovia discriminações sociais, em especial de classe e raça. Nesse espírito, embora com limitações que todo texto legal possui, as diretrizes de 2015 (BRASIL, 2015), estabeleciam que a formação de professores estava alicerçada na integração entre ensino, pesquisa e extensão. Passadas duas décadas da LDB $\mathrm{n}^{\circ}$ 9394/1996 fomos tomados pela publicação da DCN-BNC (BRASIL, 2019) que, como já descrito, dispensou o diálogo e foi redigida com estalos de chicote característica de políticas educacionais de Estados que mesclam políticas neoliberais e neoconservadoras que intencionam dificultar a autonomia de professores. 
Uma sociedade cuja base de sustentação por mais de 300 anos foi a escravização de milhares de indivíduos e que depois os relegou e impediu de acessar os bens que haviam produzido, ou seja, uma sociedade que invisibiliza seu passado em favor de um presente excludente assumido como única possibilidade, não quer possibilitar a construção de saberes múltiplos e, portanto, de novos presentes. No entanto, esta sociedade que é racista e classista também é porosa. E é na porosidade dos documentos 'oficiais' e nas lutas/práticas cotidianas que historicamente os subalternos, classes populares, os negros, os indígenas, as mulheres etc. sobreviveram. Estamos sendo desafiados a percorrer pelas possibilidades, pois os limites já os temos institucionalizados na nova legislação. Expliquemos melhor, diante do atual cenário político e educacional de retrocessos, como podemos visualizar possibilidades para formação de professores ao nos pautarmos em nossas próprias histórias de resistências e nos entendermos como professores-pesquisadores, porque o trabalho docente não é reduzido a atividades/práticas dentro de sala de aula, nosso fazer está imerso no conhecimento historicamente construído. O professor de história precisa se entender, antes de tudo, como um educador de história.

É preciso que façamos a escolha (o compromisso) pelos estudantes e não "pelos conteúdos" apenas. Isso não significa que a centralidade do processo educacional seja o aluno, longe disso, a centralidade da educação precisa ser a responsabilidade ética (BIESTA, 2017; PICOLI, GUILHERME, 2020). Para isso precisamos nos apropriar da porosidade das legislações para termos a autonomia de ser professor-pesquisador, de ser um educador. Quando nos entendemos como sujeitos da nossa ação, o currículo determinado sofrerá alterações de abordagem em nossa ação pedagógica. Entre outras ações podemos citar, a escolha de referências teóricos, a seleção de fontes, as análises de textos, a transposição voltada a realidade do estudante. São estas possibilidades que estão disponíveis para se realizar em sala de aula em todos os níveis de formação. A formação universitária tem papel central nesse debate, isso significa que as 'escolhas' nos currículos de licenciatura poderão produzir frutos saudáveis da docência. Compete aos professores universitários formadores de professores responder a demanda que se impõe: confirmar o esvaziamento da formação de seus estudantes ou procurar meios de resistir ao reducionismo e construir currículos que possam, embora sempre sem garantias, enfrentar as nossas questões (D’ÁVILA, 2020).

Considerando que a DCN-BNC é documento normativo, implica dever legal obedecê-la; considerando que a DCN-BNC subverte a formação do professor "como 
intelectual" para o professor "como técnico" executor de um currículo pronto, é dever ético desobedecê-la. Isso também se aplica a atividade do professor de História na Educação Básica com relação à BNCC. Assim, o desafio que se impõe aos professores de história na Educação Básica é encontrar brechas na BNCC que possibilite a obediência desobediente; o desafio que se impõe aos professores dos cursos de licenciatura em história é formar professores que tenham condições de fazer isso, ou seja, ao mesmo tempo em que legalmente cumprem as determinações da DCN-BNC, por assunção do dever ético, a desobedecem.

Como problematizado supra, na DCN-BNC fica clara a ênfase na prática, na técnica. Contudo, concorda-se com D’Ávila de que há, também, no disposto no documento, algumas possibilidades, embora reduzidas, de auxiliar os professores de Educação Básica em formação na construção de sua profissionalidade como intelectuais críticos e não como mero técnicos. Estas brechas também oferecem possibilidades aos professores das Instituições formadoras, especialmente das universidades, para se engajarem e não limitar sua atuação em ensinar a ensinar, mas avançar no sentido de pensar sobre o que se ensina, sobre os sentidos do que se ensina. No Art $12^{\circ}$, que versa sobre o Grupo I das DCN-BNC (BRASIL, 2019), compreendemos possíveis margens de atuação crítica as seguintes temáticas, embora a redação do documento normativo as induza como habilidades: "compreensão dos fundamentos históricos, sociológicos e filosóficos; das ideias e das práticas pedagógicas; da concepção da escola como instituição e de seu papel na sociedade; e da concepção do papel social do professor” e "entendimento sobre o sistema educacional brasileiro, sua evolução histórica e suas políticas, para fundamentar a análise da educação escolar no país, bem como possibilitar ao futuro professor compreender o contexto no qual exercerá sua prática”.

Já no grupo II, encontra-se: "vivência e aprendizagem de metodologias e estratégias que desenvolvam, nos estudantes, a criatividade e a inovação, devendo ser considerada a diversidade como recurso enriquecedor da aprendizagem”. Essas brechas precisam ser alargadas, mas isso cabe a cada docente na assunção de seu dever ético, não se quer aqui normatizar. Reafirma-se, outrossim, o caráter intelectual do professor (nas Universidades e nas escolas) que toma decisões curriculares, que faz escolhas éticas. Somos sabedores que documentos educacionais não garantem escolhas éticas, mas quando estes documentos sequer apontam para a necessidade e importância da alteridade nos processos educativos, os retrocessos tornam-se ainda evidentes e como consequências os abismos sociais, econômicos, políticos e culturais. 
Almejamos por escolhas éticas que não beneficiem a histórica ocidental fatual, mas as diferentes temporalidades e nelas o tempo presente, a história dos povos africanos, indígenas, da pluralidade que compreende a riqueza do que é humano. $\mathrm{O}$ saber histórico enquanto produção científica e social em consonância com a defesa dos direitos humanos. Reflexão sobre o saber pedagógico como desdobramento das ações históricas e das produções historiográficas. Que nossas escolhas possam proporcionar processo formativo do educador em história da Educação Básica, sem perder de vista as imposições legais, ou seja, que a carga horária e a sua distribuição já estão regulamentadas/formatada. É evidente que não há garantias de sucesso em tal empreendimento. Tal postura, a obediência desobediente, implica diálogo, implica educar não para a democracia, mas democraticamente. Implica assumir os conflitos como problemas para educação, não do tipo que exige soluções, mas do tipo que exige respostas responsáveis, respostas éticas. O diálogo é, ao mesmo tempo, um problema para a educação, porque é difícil e, talvez, até mesmo impossível, e a própria possibilidade da educação (BIESTA, 2017).

As opções teórico-metodológicas nos currículos de formação de professores serão o alicerce para os futuros professores-pesquisadores, pois a BNCC em vigor ao apresentar a área de Ciências Humanas para o Ensino Fundamental (BRASIL, 2018, p.353-356) é generalista e linear. Entendemos que não há formação ética sem pautar no debate, no ensino portanto, as questões de raça, classe e gênero que marcam profundamente nossas sociedades ao longo da história. Questões, portanto, que nos incomodam, que nos são sensíveis. A BNCC tampouco considera a importância da produção historiográfica nacional e internacional em uma perspectiva que auxilie na descolonização do currículo. Este documento ao adentrar no campo específico da história enfatiza que "o que nos interessa no conhecimento histórico é perceber a forma como os indivíduos construíram, com diferentes linguagens, suas narrações sobre o mundo em que viveram e vivem, suas instituições e organizações sociais" (BRASIL, 2018, p. 397). Apesar de não elencar questões políticas, econômicas e culturais, tal afirmação nos possibilita pensar estes sujeitos nas suas temporalidades e ações, reconhecer a singularidade, a alteridade. Nos permite afirmar que está nos docentes e alunos o protagonismo dos processos de ensino e aprendizagem. É a brecha que precisamos criar para que, seguindo a norma, o que somos obrigados por dever legal, possamos desobedecê-la, o que, se nos for possível repetir, se impõe como dever ético. 
Bloch, fuzilado pela Gestapo em 16 de julho de 1944, inicia sua obra inacabada Apologia da história com a seguinte pergunta afirmativa: "Papai, então me explica para que serve a história”, e expõe que a história:

[...] tem seus gozos estéticos próprios, que não se parecem com os de nenhuma outra disciplina. É que o espetáculo das atividades humanas, que forma seu objeto específico, é, mais que qualquer outro, feito para seduzir a imaginação dos homens. Sobretudo quando, graças a seu distanciamento no tempo ou no espaço, seu desdobramento se orna das sutis seduções do estranho (BLOCH, 2001, p. 44).

Bloch escreve em um momento que as liberdades eram cerceadas pelo fascismo, e seu legado nos provoca a pensar alternativas para a manutenção viva da disciplina história, pois não há passado sem história. Não há presente se não encaramos o passado que nos incomoda. Não há futuro se não há presente. Sem encarar os problemas estruturais de nossa sociedade, o futuro é sequestrado e o passado se impõe como norma. É um dever ético encarar a História. Nesse movimento ela não pode ser uma lista de conteúdos, assim como o professor não pode ser um técnico. O próprio tempo presente, o Agora em que nos encontramos e suas contradições, precisa ser assumido como eivado de conteúdo histórico e educativo: levantam o problema dos perigos de negligenciar a vigilância democrática. Isso implica afirmar que muito do que vivemos é devido a uma educação histórica fraca e não preocupada em estabelecer os limites, o não-mais, ou seja, uma educação histórica que não assume a legitimidade de algumas formas de medo, como o medo de perder a democracia. Pode se fazer isso através de escolhas comprometidas com a ética.

Não se quis afirmar aqui que a forma como as licenciaturas estão organizadas no Brasil (antes, portanto da DCN-BNC) caminham no sentido de educar democraticamente, de assumir a responsabilidade ética, de compreender nossos problemas estruturais como problemas educacionais. Ao contrário, a ênfase na dimensão técnica da formação docente já era a forma dominante. Precisamos, portanto, pensar a formação de professores no Brasil, nosso futuro depende disso. Entretanto, o que a DCN-BNC faz é aprofundar a crise alegando que a solução para os problemas educacionais exige maior ênfase (ainda maior) na dimensão técnica, nas práticas educacionais. Pensar os sentidos do que se ensina, já tão negligenciado em nossas licenciaturas, é, na DCN-DCN, desconsiderado como problema a ser enfrentado. A concepção da educação como tecnologia, já presente (e pode se dizer dominante) nos cursos de formação de professores, torna-se, pela DCN-BNC, a única concepção. Por 
isso a necessidade de encontrar, na porosidade da norma, meios de reivindicarmos a ética, não como conteúdo da educação, mas como elemento fundante dela. Isso, claro, se a democracia ainda foi um anseio.

Quando nos referimos a educação, não temos uma fórmula, temos caminhos a serem construídos conjuntamente entre as Universidades (Formação de professores) e os profissionais da Educação Básica. Lutar e ser vigilantes pela manutenção e ampliação das Políticas de Ações Afirmativas, para que mais e mais estudantes acessem e permaneçam nas Universidades, isto certamente impacta as estruturas historicamente estabelecidas por homens que detém privilégios. Problematizar o pensamento ocidentalbranco-cristão a partir da decolonialidade do saber e possibilitar que a diversidade de saberes seja pautada nos espaços escolares e universitários. Pois o agora se revela desafiador e exige tomada de decisão não só porque nossa sociedade muda e é mudada rapidamente (globalização, TICs, Covid-19 etc.), mas porque nossas decisões acerca de documentos políticos sobre educação devem pautar por uma educação com oportunidades e experiências de ensino e aprendizagem, pela construção de um mundo de pluralidade e diferenças, de equilíbrio entre os pressupostos teóricos e práticos da História e da Educação Histórica. Portanto, "de pessoas dispostas a assumir o risco, a arriscar-se a si mesmas para o futuro de modos humanos de existir juntas" (BIESTA, 2018, p. 29).

\section{Conclusões}

Vivemos assombrados pela nossa incapacidade, enquanto nação, de superar as mazelas estruturais da desigualdade, da fome, da má distribuição de riquezas, da injustiça, do racismo, da violência de gênero etc. Muito disso tem relação com a nossa deficiência de educação histórica: o Brasil não enfrentou como um problema sério, do ponto de vista político e educativo, a violência da Ditadura Civil-Militar que usurpou o poder entre 1964 e 1985, assim como não o fez para as deletérias consequências da escravidão e do genocídio indígena, como o racismo estrutural e a crença na existência de uma "democracia racial". Essas questões não serão enfrentadas com a melhoria nos indicadores. Não se está negando que, nos rankings, o Brasil esteja mal. Contudo, resolver a posição nos indicadores não significa que a qualidade de nossa educação melhorou. Isso pode, ao contrário, escamotear o problema: já que os testes só mensuram o que é mensurável, todo o resto que não é possível aferir em testes e que realmente importa em educação, pode continuar mal ou, ainda, piorar, haja vista que todos os 
esforços direcionar-se-ão para a melhora nos indicadores mensuráveis (BIESTA, 2009, 2018; BALL, 2012).

Ao se assumir que o objetivo da educação é melhorar os resultados, as posições nos rankings internacionais, e que os conteúdos da história tem, entre si, a mesma relevância e que, portanto, podem constar em uma lista aferível (e cronológica), que aos professores não compete realizar escolhas curriculares, que a formação docente precisa ter centralidade na prática, os nossos problemas estruturais não serão apenas fantasmas, mas brutal realidade. Ou melhor, realidade brutalizada, porque seremos incapazes de responder ao seu apelo, ao apelo que vem do outro, com quem compartilhamos o mundo. É possível que, seguindo os princípios da BNCC e da DCN-BNC, o Brasil escale posições nos ranqueamentos, o que pode ser do interesse de agências governamentais, empresariais e, até, mesmo, de setores do professorado que aderiram a esse programa. Contudo, isso não significa que conseguiremos construir novas formas, melhores, de conviver na pluralidade, afinal, não é possível medir em uma prova a qualidade de uma democracia. Com Biesta (2017) afirmamos que as coisas que realmente importam em educação não são mensuráveis. Isso não quer dizer que não importa melhorar os indicadores, mas que nada adianta isso se ainda convivermos indiferentes à injustiça. De toda forma, não se está mais falando em educação, mas de outra coisa, embora, por falta de outro nome, ainda usamos a mesma palavra.

As paixões devem nos motivar, mas não podem nos cegar, porque ao analisarmos nossa trajetória educacional pós-Ditadura Civil-Militar fica evidente que ao mesmo tempo que avançamos para uma educação democrática e plural, retrocedemos pela falta de vigilância e leituras críticas dos momentos que passamos a vivenciar, especialmente, a partir de 2014. A onda neofascista, envernizada de democracia, procura silenciar a história através da defesa da família tradicional, da moral cristã, do retorno ao regime ditatorial, da xenofobia, da naturalização do racismo etc. Esse conjunto resultou no ataque a educação formal, as universidades e aos currículos de formação de professores. Se voltou contra tudo que tenha pretensão intelectual, por isso, se volta contra a formação de professores como intelectuais.

Em uma nação permeada pelo racismo estrutural estes discursos foram absorvidos por grande parte das classes populares, e em maior proporção pela classe média, uma escola que não se oponha a isso é qualquer coisa, mas não é mais uma escola. Uma universidade que não se aventura na incerteza da construção de um mundo mais justo e plural não pode mais ser uma universidade. Para além de ações pontuais, 
geralmente realizadas em sala de aula, é imprescindível ações que envolvam estudantes, professores e comunidades de suas inserções e dos diferentes níveis educacionais para problematizar e propor caminhos para a construção e ampliação de uma educação democrática (que assuma como questão educacional o medo de perder a democracia), inclusiva da pluralidade, e na qual seus partícipes sintam-se representados e incluídos. Frente ao reducionismo da história e ao esvaziamento do caráter educativo da escola e da universidade, presente em documentos como a BNCC e a DCN-BNC, urge o dever ético de resistir, o dever ético de desobedecer para que possamos almejar uma educação histórica que enfrente os nossos problemas de uma forma como até então não fomos capazes de fazer.

\section{Referências}

ALMEIDA, Silvio Luiz de. Racismo estrutural. São Paulo: Pólen, 2019.

ALVAREDO, Facundo; ET ALL. World Inequality Report. Berlin: World Inequality Lab., 2018.

ANPED. Uma formação formatada. ANPEd, 2019. Disponível em http://www.anped.org.br/sites/default/files/images/posicao_da_anped_sobre_o_texto_re ferenciadiretrizes_curriculares_nacionais_e_base_nacional_comum_para_a_formacao_i nicial_e_continuada_de_professores_da_educ.pdf. Acesso em: 22 fev. 2020.

ANPUH. Nota sobre a Segunda Versão da BNCC. 2016. Disponível em https://anpuh.org.br/index.php/2015-01-20-00-01-55/noticias2/diversas/item/3574-notasobre-a-segunda-versao-da-bncc. Acesso em: 19 nov. 2019.

[Correspondência]. Destinatário Conselho Nacional de Educação. 2017.

Disponível em: https://www.anpuh.org.br/index.php/2015-01-20-00-0155/noticias2/noticias-destaque/item/4484-carta-da-diretoria-da-associacao-nacional-dehistoria-ao-conselho-nacional-de-educacao-cne-reflexoes-e-subsidios-da-anpuh-arespeito-da-bncc. Acesso em: 22 fev. 2020.

ANTUNES, Marina Ferrreira de Souza. O currículo como materialização do Estado gerencial: a BNCC em questão. Movimento-Revista de Educação, Niterói, v. 6, n. 10, p. 43-64, jan./jun. 2019.

BALL, Stephen John. Reforma educacional como barbárie social: economismo e o fim da autenticidade. Práxis Educativa, v. 7, n. 1, p. 33-52, jan./jun. 2012.

BBC BRASIL. 'Fui agredido em sala de aula': 3 professores contam histórias de violência, trauma e decepção. 12 ago. 2019. Disponível em: https://www.bbc.com/portuguese/brasil-49301295. Acesso em: 20 mar. 2020. 
BIESTA, Gert. Good Education in an Age of Measurement. Educational Assessment, Evaluation and Accountability, v. 21, n. 1. p. 33-46, 2009.

Para além da aprendizagem: educação democrática para o futuro humano. Tradução de Rosaura Eichenberg. Belo Horizonte: Autêntica, 2017.

O dever de resistir: sobre escolas, professores e sociedade. Tradução Bruno Antonio Picoli. Educação, Porto Alegre, v. 41, n. 1, p. 21-29, jan./abr. 2018.

BITTENCOURT, Circe (org.). O saber histórico em sala de aula. São Paulo: Contexto, 2004.

. Ensino de história: fundamentos e métodos, São Paulo: Cortez, 2018.

BLOCH, Marc. Apologia da história, ou, o ofício de historiador. Tradução André Telles. Rio de Janeiro: Zahar, 2001.

BRASIL. Lei No 9.394, de 20 de dezembro de 1996. Estabelece as diretrizes e bases da educação nacional. Diário Oficial da União: seção 1, Brasília, DF, n. 248, p. 27833 27841, 23 dez. 1996.

Base Nacional Comum Curricular: educação é a base. Brasília: MEC, 2018.

Disponível

em: https://basenacionalcomum.mec.gov.br/images/BNCC_EI_EF_110518_versaofinal_site. pdf. Acesso em: 23 mar. 2020.

Resolução $N^{o}$ 2, de 01 de julho de 2015: Define as Diretrizes Curriculares Nacionais para Formação Inicial e Continuada de Professores da Educação Básica. Disponível em: http://portal.mec.gov.br/index.php?option=com_docman\&view=download\&alias $=1367$ 31-rcp002-15-1\&category_slug=dezembro-2019-pdf\&Itemid=30192. Acesso em: 24 mar. 2020.

Resolução $N^{o}$ 2, de 20 de dezembro de 2019. Diretrizes Curriculares Nacionais para a Formação Inicial de Professores para a Educação Básica e a Base Nacional Comum para a Formação Inicial de Professores da Educação Básica. Disponível em: http://portal.mec.gov.br/docman/dezembro-2019-pdf/135951-rcp002-19/file. Acesso em: 24 mar. 2020.

CAIMI, Flávia Eloisa. Conversa e controvérsias: O ensino de história no Brasil. Passo Fundo: Editora da UPF, 2001.

COUTO NETO, Geraldo Homero do. A "nova direita" no youtube: conservadorismo e negacionismo histórico sobre a ditadura militar brasileira. Revista Ágora, Vitória, n. 29, p. 83-103, 2019.

D'ÁVILA, Cristina. A didática nas Diretrizes Curriculares Nacionais e Base Nacional Comum para a Formação de Professores da Educação Básica: impasses, desafios e resistências. Revista Cocar, Belém, n. 8, p. 86-101, 2020. 
GONÇALVES, Suzane da Rocha Vieira; MOTA, Maria Renata Alonso; ANADON, Simone Barreto. A Resolução CNE/CP n. 2/2019 e os retrocessos na formação de professores. Formação em Movimento, v. 2, n. 4, pp. 360-379, 2020.

GUR-ZE'EV, Ilan. Beyond postmodern feminist Critical Pedagogy: Toward a Diasporic philosophy of conter-education. In: GUR-ZE'EV, Ilan. (org.). Critical theory and critical pedagogy today: toward a new critical language in education. Haifa: Universidade de Haifa, 2005. p. 160-192.

HOBSBAWM, Eric. Sobre história. Tradução Cid Knipel Moreira. São Paulo: Cia das Letras, 2013.

HYPOLITO, Álvaro Moreira. BNCC, agenda global e formação docente. Retratos da Escola, Brasília, v. 13, n. 25, p. 187-201, jan./maio 2019.

INEP. Relatório do $2^{o}$ Ciclo de Monitoramento das Metas do Plano Nacional de Educação - 2018. Brasília: INEP, 2018.

MIGUEL, Luis Felipe. Da "doutrinação marxista" à "ideologia de gênero" - Escola Sem Partido e as leis da mordaça no parlamento brasileiro. Direito e Práxis, Rio de Janeiro, v. 7, n. 15, p. 590-621, 2016.

NOWAK, Matthias. Feminicide: A Global Problem. Small Arms Survey Research Notes, 14, 2012.

OCDE. Brazil - Country Note - PISA 2018 Results, 2019. Disponível em: https://www.oecd.org/pisa/publications/PISA2018_CN_BRA.pdf. Acesso em: 20 mai. 2020.

TALIS 2018 Results (Volume II): Teachers and School Leaders as Valued Professionals, Talis, OECD Publishing, Paris, 2020.

OLIVEIRA, José Marcelo Domingos de; MOTT, Luis (org). Mortes violentas de $L G B T+$ no Brasil - 2019: Relatório do Grupo Gay da Bahia. Salvador: Editora Grupo Gay da Bahia, 2020.

PICOLI, Bruno Antonio. Base Nacional Comum Curricular e o canto da sereia da educação normalizante: a articulação neoliberal-neoconservadora e o dever éticoestético da resistência. Revista de Estudios Teóricos y Epistemológicos en Política Educativa, Ponta Grossa, v. 5, p. 1-23, 2020.

; GUILHERME, Alexandre Anselmo. Memória, ética e estética: algumas considerações a partir de Adorno, Levinas e Gur-Ze'ev. Veritas, Porto Alegre, v. 65, n. 2, pp. 1-11, 2020.

; RADAELLI, Samuel Mânica; TEDESCO, Anderson Luiz. Antiintelectualismo, neoconservadorismo e reacionarismo no Brasil contemporâneo: o movimento escola sem partido e a perseguição aos professores. Revista Educação e Contemporaneidade - FAEEBA, Brumado, v. 29, n. 58, pp. 48-66, 2020. 
PICOLI, Bruno Antonio; VICENZI, Renilda. Training History Teachers in Brazil: New Guidelines for Teacher Training under the Common National Curricular Base. In: Peters M. (eds) Encyclopedia of Teacher Education. Singapore: Springer, 2020.

PIMENTA, Selma; LIMA, Maria Socorro Lucena. Estágio e Docência. São Paulo: Cortez, 2004.

QUEIROZ GUEDES, Marilde Queiroz. Política de formação docente: as novas diretrizes e a base nacional comum instituídas. Sul-Sul - Revista De Ciências Humanas e Sociais, v. 1, n. 1, pp. 82-103, 2020. Disponível em: https://revistas.ufob.edu.br/index.php/revistasul-sul/article/view/658 Acesso em 08 out. 2020.

SANTOS, André Vitor dos; FERREIRA, Marcia. Currículo Nacional Comum: uma questão de qualidade? Em Aberto, v. 33, n. 107, pp. 27-44, 2020.

SCHWARCZ, Lilia. Sobre o autoritarismo brasileiro. São Paulo: Cia das Letras, 2019.

SILVA, Maurício. Cotas raciais na universidade brasileira e a ideologia da meritocracia. Educação, Cultura e Sociedade, Sinop, v. 8, n. 1, p. 209-219, jan./jun, 2018.

UOL. Weintraub ameaça tirar mural de Paulo Freire do MEC: 'Fracasso da educação', 7 mai. 2020.2 Disponível em: https://educacao.uol.com.br/noticias/2020/05/07/weintraub-ameaca-tirar-mural-depaulo-freire-do-mec-fracasso-da-educacao.htm. Acesso em: 8 mai. 2020.

VEJA. Professores mal formados: como contornar esse problema. 8 jan. 2015. Disponível em: https://veja.abril.com.br/educacao/professores-mal-formados-comocontornar-esse-problema/. Acesso em: 21 mai. 2020.

ZANOTTO, Marijane; SANDRI, Simone. Avaliação em larga escala e BNCC: estratégias para o gerencialismo na educação. Temas \& Matizes, Cascavel, v. 12, n. 23, p. 127-143, jul./dez. 2018.

Artigo recebido em 15 de junho de 2020. Aprovado em 18 de novembro de 2020. 